\title{
Allicin enhances host pro-inflammatory immune responses and protects against acute murine malaria infection
}

Yonghui Feng ${ }^{1}$, Xiaotong Zhu' ${ }^{1}$, Qinghui Wang ${ }^{1}$, Yongjun Jiang ${ }^{2,3}$, Hong Shang ${ }^{2,3}$, Liwang Cui ${ }^{4}$ and Yaming Cao ${ }^{1 *}$

\begin{abstract}
Background: During malaria infection, multiple pro-inflammatory mediators including IFN- $\gamma$, TNF and nitric oxide (NO) play a crucial role in the protection against the parasites. Modulation of host immunity is an important strategy to improve the outcome of malaria infection. Allicin is the major biologically active component of garlic and shows anti-microbial activity. Allicin is also active against protozoan parasites including Plasmodium, which is thought to be mediated by inhibiting cysteine proteases. In this study, the immunomodulatory activities of allicin were assessed during acute malaria infection using a rodent malaria model Plasmodium yoelii 17XL.
\end{abstract}

Methods: To determine whether allicin modulates host immune responses against malaria infection, mice were treated with allicin after infection with $P$. yoelii $17 X \mathrm{~L}$. Mortality was checked daily and parasitaemia was determined every other day. Pro-inflammatory mediators and IL-4 were quantified by ELISA, while NO level was determined by the Griess method. The populations of dendritic cells (DCs), macrophages, $C D 4^{+} T$ and regulatory $T$ cells (Treg) were assessed by FACS.

Results: Allicin reduced parasitaemia and prolonged survival of the host in a dose-dependent manner. This effect is at least partially due to improved host immune responses. Results showed that allicin treatment enhanced the production of pro-inflammatory mediators such as IFN- $\gamma$, TNF, IL-12p70 and NO. The absolute numbers of CD4 ${ }^{+} \mathrm{T}$ cells, DCs and macrophages were significantly higher in allicin-treated mice. In addition, allicin promoted the maturation of CD11 $\mathrm{C}^{+} \mathrm{DCs}$, whereas it did not cause major changes in IL-4 and the level of anti-inflammatory cytokine IL-10.

Conclusions: Allicin could partially protect host against $P$. yoelii 17XL through enhancement of the host innate and adaptive immune responses.

Keywords: Pro-inflammatory mediators, Plasmodium yoelii, Dendritic cells, Macrophages

\section{Background}

Malaria with its $\sim 250$ million clinical cases and a human death toll of 0.9 million per year remains a huge problem in many tropical and subtropical countries [1]. To realize the ambitious goal of malaria elimination, novel integrated strategies are needed. Among them, vaccines to reduce the morbidity and mortality associated with malaria have been intensively pursued, but so far no malaria vaccine is available. Vaccine development efforts

\footnotetext{
*Correspondence: ymcao@mail.cmu.edu.cn

'Department of Immunology, College of Basic Medical Sciences, China

Medical University, Shenyang, Liaoning, China

Full list of author information is available at the end of the article
}

are thwarted partially by incomplete understanding of the mechanisms of protective immunity against malaria, which normally develops in populations residing in hyperendemic areas after repeated exposure to malaria infections.

To identify the key targets and mechanisms of protective immunity against malaria, experimental murine malaria models have significantly advanced our understanding of how Plasmodium parasites interact with the host immune responses in vivo [2]. It has become evident that Th1 type pro-inflammatory immune responses are essential for controlling the parasite load during the early phase of infection [3-5]. Protective $\mathrm{CD}_{4}^{+} \mathrm{T}$ cells release IFN- $\gamma$ to

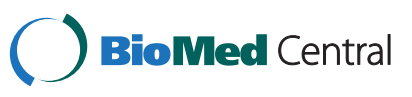


activate effector cells such as macrophages, which may exert anti-malarial effects by releasing TNF and nitric oxide (NO) [6,7]. NO can reduce parasitaemia during the initial phase of blood-stage malaria infection $[8,9]$. During malaria infection, regulatory $\mathrm{T}$ cells (Treg) can expand and suppress the establishment of Th1 immune response [10], resulting in increased parasitaemia and mortality of the host [11,12]. Dendritic cells (DCs) are critical players in innate immunity and priming $\mathrm{T}$ cell-dependent, specific immune responses to malaria infection. DCs activated in the spleen are major antigen-presenting cells (APCs), and also a source of cytokines that help shape up cell-mediated and humoral immunity $[13,14]$. Therefore, immunomodulatory drugs that improve the functions of DCs may lead to enhanced immunity against malaria parasites.

Many natural products possess immunomodulatory activities, which have long been sought for treating human diseases. Garlic (Allium sativum) is one of the most ancient vegetables and its medicinal uses are dated back $>5,000$ years [15]. Garlic possesses evident pharmacological properties, such as antimicrobial [16,17], antioxidant $[18,19]$, and anticancer activities [20,21]. Garlic and its components have potent antiparasitic activities against many human and animal parasites [22], such as Leishmania [23,24], Schistosoma [25,26], Trypanosoma, Giardia, Entamoeba [27,28], and Plasmodium [29,30]. Allicin (diallyl thiosulfinate), rapidly converted from allin by allinase in crushed fresh garlic cloves, is a major component and thiosulphinate compound responsible for the biological activity of garlic [31]. A recent study reported that the potent anti-plasmodial and anti-trypanosomal activity of allicin is associated with its inhibitory effect on the cysteine proteases of the parasites [32]. In addition to the proclaimed nutritional and antimicrobial effects [33], garlic has immunomodulatory activities [15,34]. As an immune stimulant, garlic components stimulate the proliferation of splenocytes $[34,35]$ and synthesis of $\mathrm{NO}$ and TNF [36,37]. However, under certain circumstances, allicin or garlic extract may also work as an immune suppressant to down-regulate inflammatory responses and inhibit the interaction of T cells with the endothelial cells [38].

Although the anti-parasitic effects of garlic extract and allicin have been investigated, little is known about the immunomodulatory effects of garlic on parasitic infections. In Leishmania major-infected susceptible mice, treatment with garlic extract promoted the shift towards a Th1 response and enhanced the phagocytic activity of peritoneal macrophages, which significantly improved the disease outcome $[39,40]$. Here, the murine malaria model was used to investigate the effects of allicin on the course of infection of BALB/c mice with the lethal strain of Plasmodium yoelii 17XL. The results indicated that allicin treatments promoted the production of pro- inflammatory mediators and protected the host from Plasmodium infection.

\section{Methods}

Mice, parasite, and infection

Female, six to eight weeks old, BALB/c mice were purchased from Academia Sinica Shanghai experimental animal centre. Plasmodium yoelii 17XL infections were initiated by intraperitoneal (IP) injection of $1 \times 10^{6} \mathrm{P}$. yoelii 17XL parasitized red blood cells (pRBCs) per mouse. Parasitaemia was determined every other day by light microscopic examination of at least 1,000 erythrocytes on Giemsa-stained blood smears. Mortality was checked daily. All experiments were performed in compliance with local animal ethics committee requirements.

\section{Allicin treatment}

Allicin was purchased from Jinkongfu Pharmaceutical (Wuhan, China). The stock solution was prepared by dissolving allicin in ethanol at a concentration of $10 \mathrm{mg} / \mathrm{ml}$. It was diluted to $1 \mathrm{mg} / \mathrm{ml}$ with phosphate buffered saline (PBS) before use. For animal experiment, BALB/c mice were randomly divided into three groups. Allicin was orally administered by gavage at a dose of 3 or $9 \mathrm{mg} / \mathrm{kg} /$ day on days $0-2$ post-infection (PI). Mice in the control group received $0.2 \mathrm{ml} \mathrm{PBS}$ at the same time points. Three mice in each group were sacrificed on day 3 and 5, respectively. The experiment was repeated three times.

\section{Spleen cell culture and quantification of cytokines}

Spleens from BALB/c mice were removed aseptically and splenocytes were cultured as previously described [41]. Splenocytes were adjusted to a final concentration of $1 \times 10^{7}$ cells $/ \mathrm{ml}$ in RPMI1640 supplemented with $10 \%$ heat-inactivated foetal calf serum (FCS). Aliquots of the cell suspension $\left(5 \times 10^{6}\right.$ cells/well $)$ were seeded into 24-well, flat-bottom, tissue culture plates in triplicate, and incubated for $48 \mathrm{hr}$ at $37^{\circ} \mathrm{C}$ in a humidified $5 \%$ $\mathrm{CO}_{2}$ incubator. The supernatants were collected and stored at $-80^{\circ} \mathrm{C}$ until assayed for cytokines.

Levels of IFN- $\gamma$, TNF, IL-12p70, IL-4 and IL-10 were measured by commercial enzyme-linked immunosorbent assay (ELISA) kits according to the manufacturer's protocols (R\&D Systems, Minneapolis, MN, USA). As a measure of $\mathrm{NO}$ production, concentrations of $\mathrm{NO}_{2}^{-}$in cell culture supernatants were determined by the Griess reaction [42].

\section{Flow cytometry}

At the indicated time points, splenocytes were obtained from infected BALB/c mice for flow cytometric analysis to determine the subsets of spleen DCs: $\mathrm{CD} 11 \mathrm{c}^{+} \mathrm{CD} 11 \mathrm{~b}^{+}$ myeloid DCs (mDCs) and $\mathrm{CD} 11 \mathrm{c}^{+} \mathrm{CD} 45 \mathrm{R} / \mathrm{B} 220^{+}$plas- 

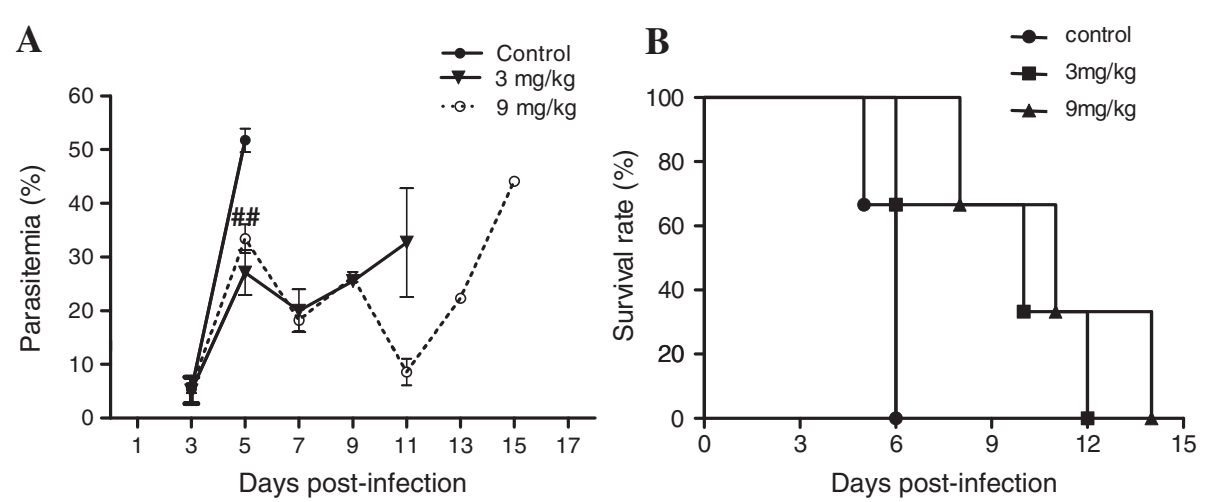

Figure 1 Effects of allicin treatment on parasitaemia and survival of $P$. yoelii $17 \mathrm{XL}$ infected mice. Mice were treated with two doses of allicin ( 3 and $9 \mathrm{mg} / \mathrm{kg}$ ) and PBS (control group) for successive three days after P. yoelii $17 \mathrm{XL}$ infection. Parasitaemia was calculated by counting the number of parasite-infected erythrocytes per 1,000 erythrocytes. Mortality was monitored daily. Results are presented as arithmetic mean of three mice per group \pm the standard error of the mean (SEM). \#\#, significant difference $(P<0.001)$ compared to the control group.

macytoid DCs (pDCs), the population of CD11 ${ }^{+} \mathrm{DCs}$ expressing MHCII or TLR9, macrophages and Treg. Antibodies and their sources were described previously [41]. Flow cytometry was performed on a FACS Calibur (BD Biosciences, San Diego, CA, USA) and analysed using the FlowJo software (Treestar, San Carlos, CA, USA).

\section{Statistical analysis}

For each experiment, three mice were used to obtain an average, and the average values from three experiments were used to calculate the mean and standard error (SEM). Statistical analysis was performed by one-way ANOVA using the statistical software SPSS version 16.0. Fisher's LSD post-hoc test was applied to assess differences of each group. Time-to-event data were statistically analysed with the Kaplan-Meier approach to survival analysis using the statistical software SPSS version 16.0. $P$ values less than 0.05 were considered statistically significant.

\section{Results}

\section{Allicin improves survival by reducing parasitaemia}

The $P$. yoelii $17 \mathrm{XL}$ strain is highly virulent to $\mathrm{BALB} / \mathrm{c}$ mice and causes lethal infection. In the control group, parasitaemia rose sharply and reached a peak level $(51.8 \%)$ on day 5 PI (Figure 1A) and all mice died by day 7 (Figure 1B). In contrast, three-day oral allicin treatments at two dosages significantly reduced the day 5 parasitaemias $(27.1 \%$ and $32.6 \%$ for the 3 and $9 \mathrm{mg} / \mathrm{kg}$ groups, respectively). Further decline of the parasitaemia was noticed on day 7 PI in both allicin treatment groups (Figure 1A). Consistent with an earlier observation on the effect of allicin on Plasmodium berghei erythrocytic infection [30], allicin treatments at both dosages significantly extended the survival time of infected mice $(P<0.05$ and $P<0.01$ compared to NC group by Kaplan-Meier's

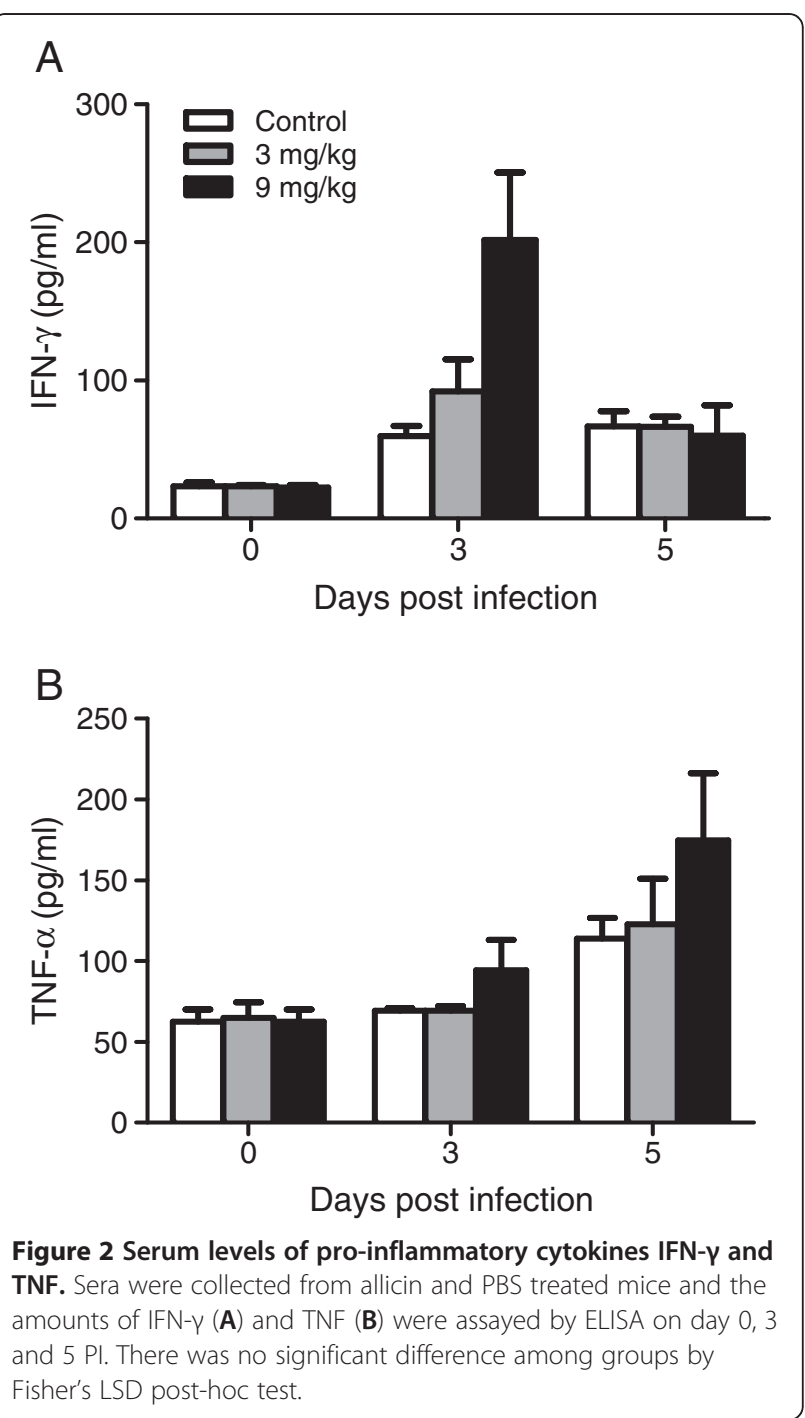


statistics, respectively); all mice died by day 13 and 15 , respectively (Figure 1B).

\section{Allicin preferentially enhances pro-inflammatory immune responses}

As a cysteine protease inhibitor, the inhibitory effects of allicin on Plasmodium parasites were attributed to the direct action on parasites [30,32]. Because allicin also has immunomodulatory activity, whether improved disease outcomes by allicin treatments could result from strengthened host immunity against Plasmodium infection was investigated. Previous studies have shown that enhancement of Th1 responses during $P$. yoelii 17XL infection could reduce the initial parasite load and extend host survival time [43]. Here, the levels of several pro-inflammatory mediators in the sera of control and allicin-treated mice were evaluated. Allicin treatments increased IFN- $\gamma$ levels on day 3 PI and treatment at $9 \mathrm{mg} / \mathrm{kg}$ increased TNF levels on both days 3 and 5 PI, although the differences were not statistically significant (Figure 2). To further investigate whether the elevated serum levels of pro-inflammatory cytokines were the result of increased production in splenocytes, the in vitro synthesis of IFN- $\gamma$, TNF, IL-12p70 and NO in cultured splenocytes from the control and allicin-treated mice were measured. Compared to the control, allicin treatments at both dosages caused significant increases in the production of IFN- $\gamma$ and TNF by splenocytes on days 3 and 5 PI $(P<0.05)$ and the effect appeared to be dose-dependent (Figure 3A, B). More specifically, $9 \mathrm{mg} / \mathrm{kg}$ allicin treatment led to seven times higher production of IFN- $\gamma$ than $3 \mathrm{mg} / \mathrm{kg}$ allicin treatment on day 3 PI (Figure $3 \mathrm{~A}$ ). IFN- $\gamma$ can promote the production of NO by macrophages to reduce the parasitaemia during $P$. yoelii 17XL infection. Therefore, NO production in cultured splenocytes, a hallmark of
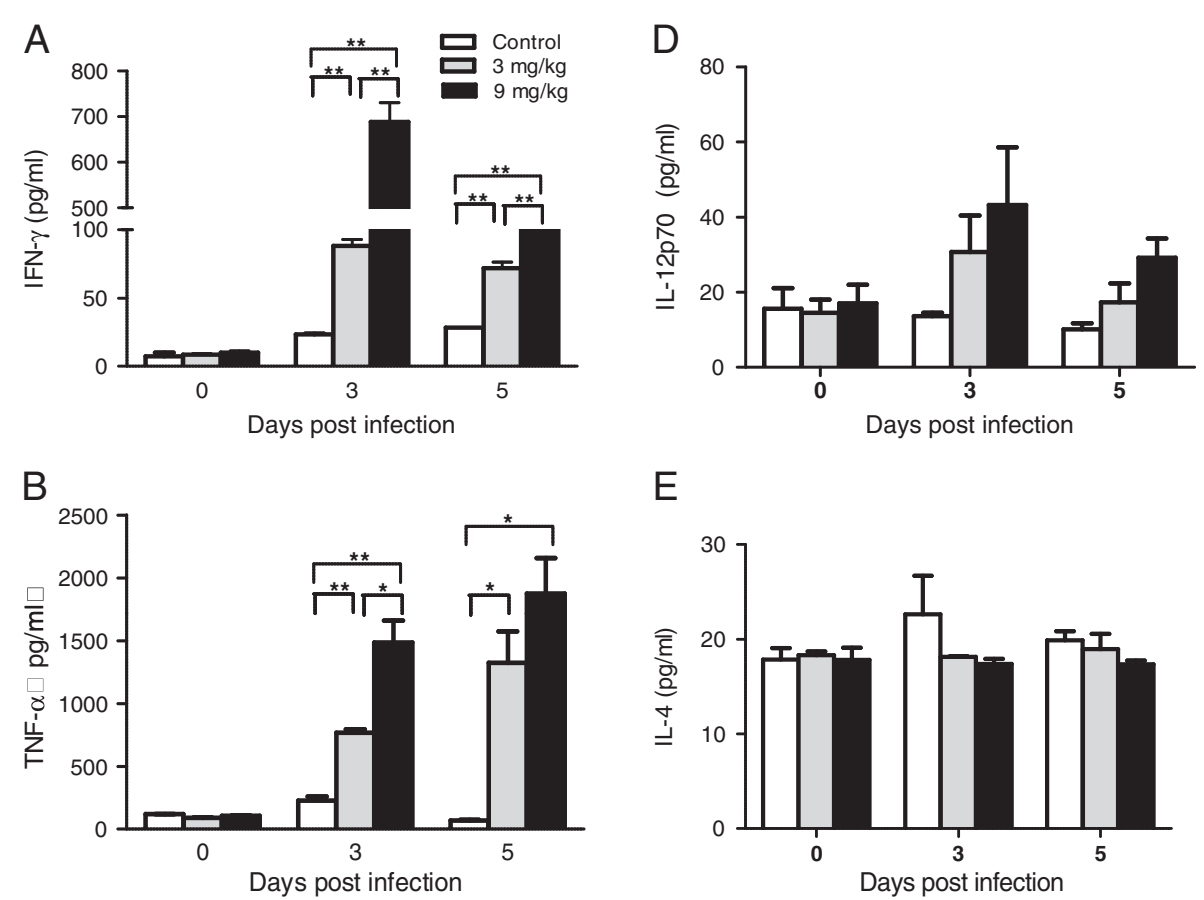

E
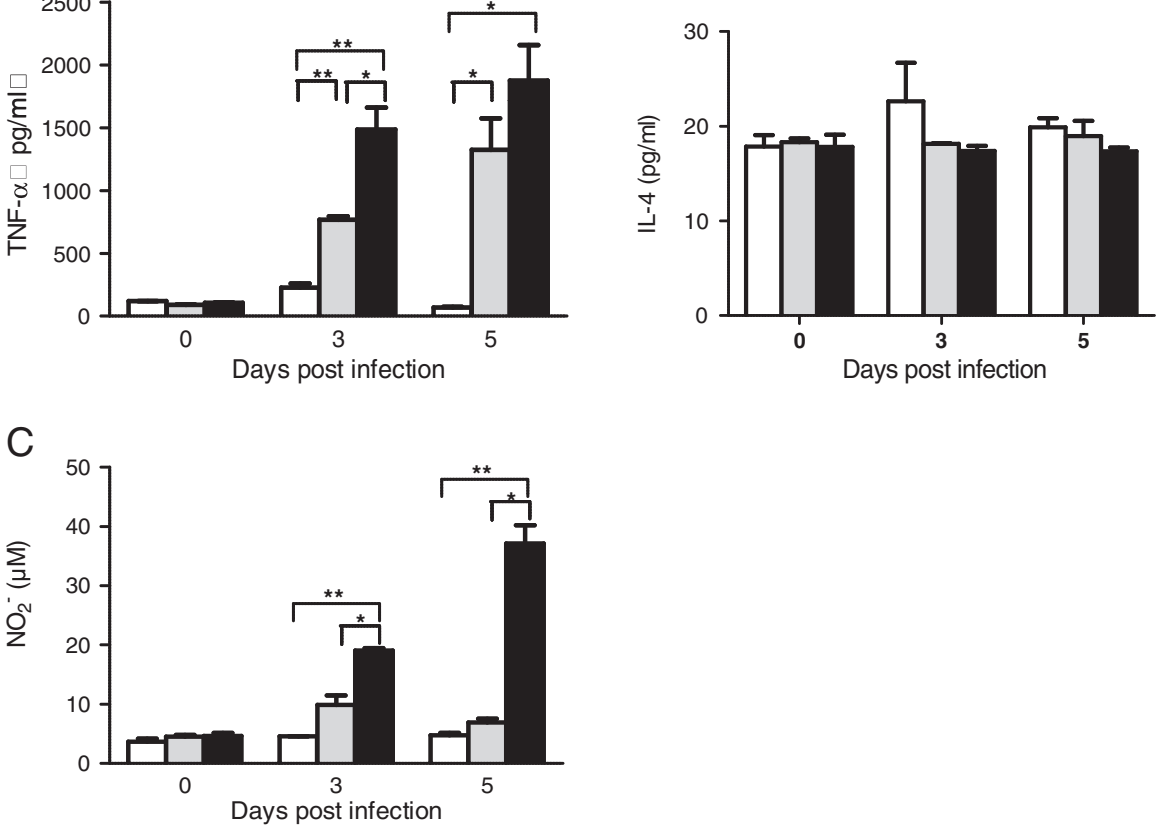

Figure 3 Effects of allicin on pro-inflammatory immune responses during murine malaria infection. On day 0,3 and 5 after infection, spleen cells were prepared and concentrations of IFN- $\gamma(\mathbf{A})$, TNF (B), IL-12p70 (D) and IL-4 (E) were determined by ELISA. The concentration of $\mathrm{NO}_{2}^{-}$(C) was detected using the Griess reaction. 
macrophage activation, was further studied. In support of earlier observation of other Th1 cytokines, both allicin treatment dosages increased $\mathrm{NO}$ production on days 3 and $5 \mathrm{PI}$ (Figure $3 \mathrm{C}$ ). Yet, the $3 \mathrm{mg} / \mathrm{kg}$ treatment group showed slight, insignificant increase of NO production as compared to control (Figure $3 \mathrm{C}, P>0.05$ ). Significant increase in $\mathrm{NO}_{2}^{-}$was evident in the higher dose $(9 \mathrm{mg} / \mathrm{kg})$ of allicin treatment group (Figure 3C). IL-12 is an important stimulator of the $\mathrm{T}$-cell response and plays a critical role in resistance to malaria [44-46]. Allicin treatments at both dosages caused increases in the production of IL-12p70 by splenocytes on days 3 and $5 \mathrm{PI}$ and this effect also appeared to be dose-dependent, albeit the difference was not statistically significant (Figure $3 D, P>0.05$ ). To evaluate whether allicin treatment affected Th2 immune response during the early stage of $P$. yoelii $17 \mathrm{XL}$ infection, the amount of IL-4 in the supernatant of cultured splenocytes was determined, and there was no significant difference between the experiment and control groups (Figure 3E, $P>0.05$ ). Altogether, these results showed that allicin treatment preferentially promoted the production of pro-inflammatory mediators during acute malaria infection in a dose-dependent manner.

\section{Allicin treatments stimulate expansion of $\mathrm{CD}^{+} \mathrm{T}$ cells and macrophages}

Protective immunity against blood-stage Plasmodium requires malaria-specific $\mathrm{CD}^{+} \mathrm{T}$ cells to rapidly and effectively control parasitaemia and clear the infection [47]. In addition, macrophages also play an essential role for parasite control during the early acute phase infection by the lethal $P$. yoelii strain [9]. Whereas significant changes in the number of $\mathrm{CD}^{+} \mathrm{T}$ cells in both allicin treatment groups on day 3 PI were observed, spleen $\mathrm{CD}^{+} \mathrm{T}$ cell expansion was detected on day $5 \mathrm{PI}$ (Figure 4A). Again, this change in spleen $\mathrm{CD}^{+} \mathrm{T}$ cell was only evident in the $9 \mathrm{mg} / \mathrm{kg}$ allicin-treated group. Similarly, mice treated with $9 \mathrm{mg} / \mathrm{kg}$ of allicin had significantly more macrophages in the spleen than either control or $3 \mathrm{mg} / \mathrm{kg}$ allicin-treated mice (Figure 4B).

\section{Allicin treatments promote the activation of dendritic cells}

DCs are the critical link between innate and adaptive immune responses. Two subpopulations of DCs are defined as $\mathrm{mDCs}\left(\mathrm{CD} 11 \mathrm{c}^{+} \mathrm{CD} 11 \mathrm{~b}^{+}\right)$and $\mathrm{pDCs}\left(\mathrm{CD} 11 \mathrm{c}^{+}\right.$ $\left.\mathrm{CD} 45 \mathrm{R} / \mathrm{B} 220^{+}\right)$. On day $3 \mathrm{PI}$, the numbers of $\mathrm{mDCs}$ were not significantly different between the allicin treatment groups and control (Figure 5A). However, $9 \mathrm{mg} / \mathrm{kg}$ allicin significantly suppressed the total number of spleen pDCs (Figure 5B). On day $5 \mathrm{PI}$, allicin treatment at $3 \mathrm{mg} / \mathrm{kg}$ produced more $\mathrm{mDCs}$ and $\mathrm{pDCs}$, albeit the increases were not statistically significant. In comparison, the numbers of both DC populations on
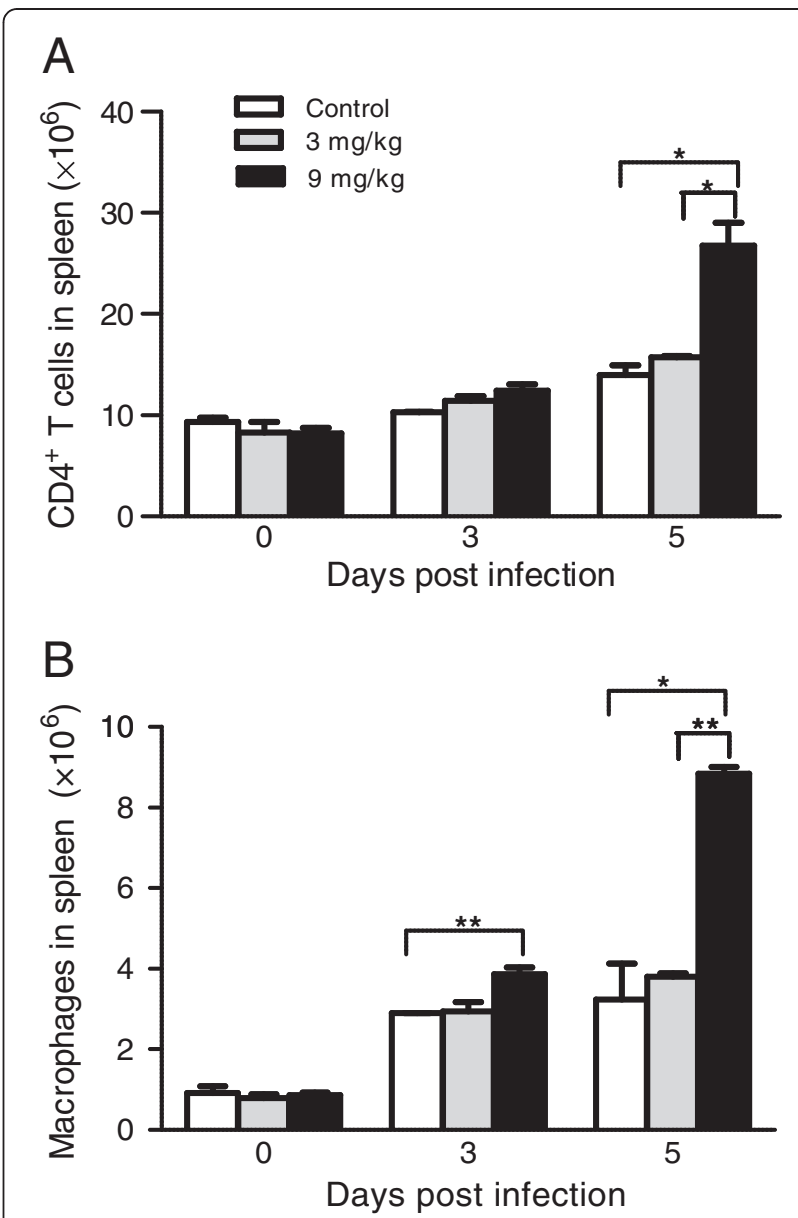

Figure 4 Effects of allicin treatments on $\mathrm{CD}^{+} \mathrm{T}$ cells and macrophages during $P$. yoelii $17 \mathrm{XL}$ infection. Absolute numbers of $\mathrm{CD}^{+} \mathrm{T}$ cells $(\mathbf{A})$ and macrophages $(\mathbf{B})$ were quantified by flow cytometry at day 0,3 and $5 \mathrm{PI}$. One experiment representative of three is shown. Error bars represents SEM. Asterisks indicate statistically significant differences (*: $P<0.05$; $\left.{ }^{* *}: P<0.01\right)$ between groups.

day $5 \mathrm{PI}$ in the $9 \mathrm{mg} / \mathrm{kg}$ allicin treatment group were significantly higher than those in the control or $3 \mathrm{mg} / \mathrm{kg}$ allicin treatment groups (Figure 5A, B).

Maturation of DCs is essential to induce Th1 immune response for antigen presentation to $\mathrm{T}$ cells [48]. To study whether allicin treatment had any effect on activation of DCs, the numbers of DCs expressing MHCII and TLR9 between the control and treatment groups were compared. Infection with $P$. yoelii $17 \mathrm{XL}$ significantly increased the total numbers of mature DCs expressing MHC II on day $3 \mathrm{PI}$, but no significant difference was observed among the treatment groups (Figure $5 \mathrm{C}$ ). On day $5 \mathrm{PI}$, however, $9 \mathrm{mg} / \mathrm{kg}$ allicin treatment group produced significantly more MHC II-expressing DCs than control $(P<0.05)$ or $3 \mathrm{mg} / \mathrm{kg}$ allicin treatment group $(P<0.01)$ (Figure $5 C)$. Analysis of TLR9-expressing DCs revealed a similar trend as that of the MHCII-expressing 

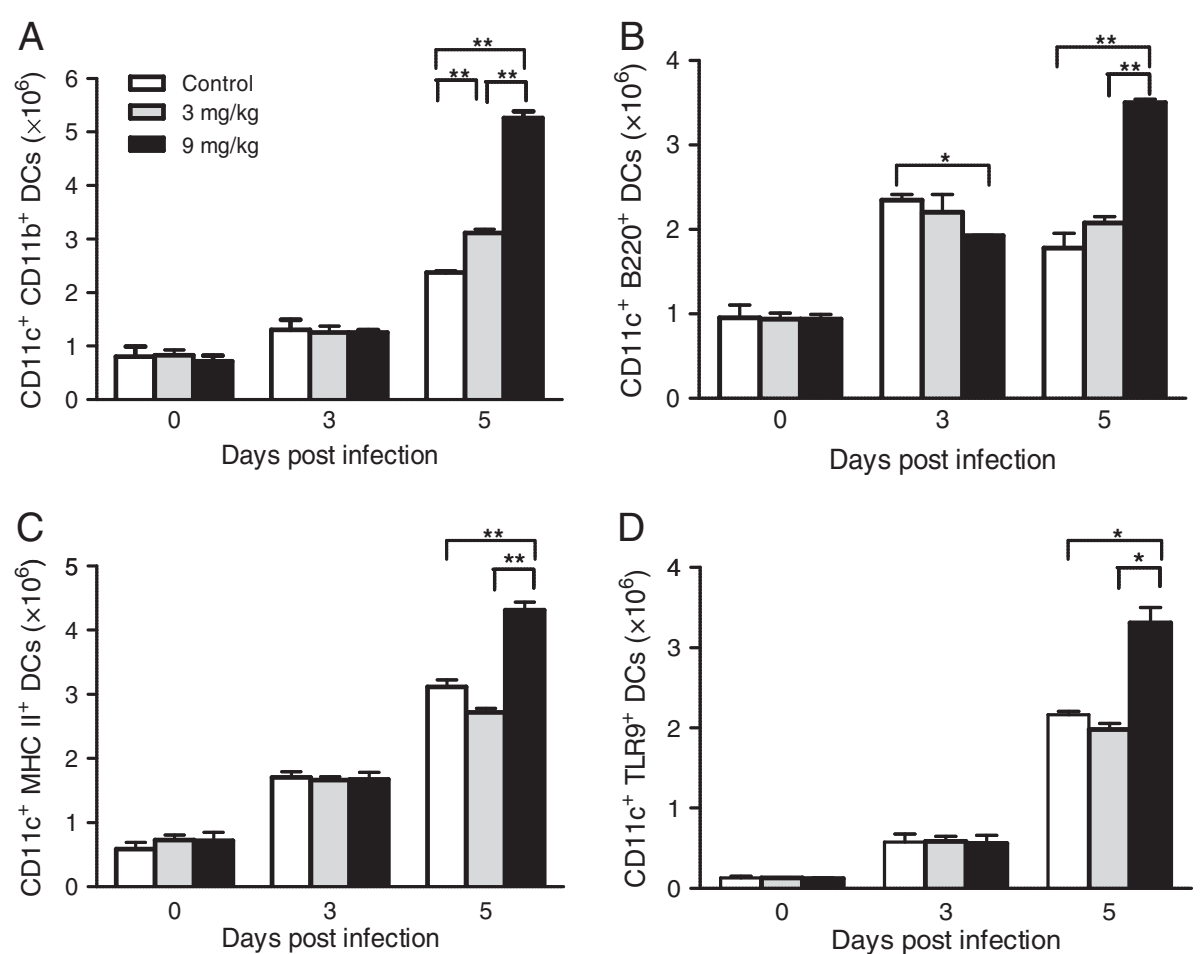

Figure 5 Effects of allicin treatments on DCs during $P$. yoelii 17XL infection. Representative graphs show the absolute numbers of cells in

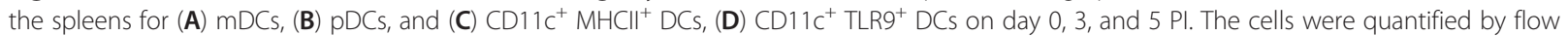
cytometry analysis and data presented as the mean \pm standard error $(n=3$ mice/group). Results are representative of three independent experiments. Error bars represents SEM. Asterisks indicate statistically significant differences (*: $\left.P<0.05 ;{ }^{* *}: P<0.01\right)$ between groups.

DCs (Figure 5D). Collectively, these results indicate that allicin treatment at $9 \mathrm{mg} / \mathrm{kg}$ promoted expansion of matured DCs and enhanced TLR9-mediated innate immune activation on day 5 during $P$. yoelii 17XL infection.

\section{Allicin has no effect on IL-10 production or Treg}

The immunomodulatory functions of allicin can also down-regulate the inflammatory response [49-51]. The effect of allicin treatment on Treg, which has an inhibitory effect on Th1 immune response, and the antiinflammatory cytokine IL-10 was examined. Only allicin treatment at $9 \mathrm{mg} / \mathrm{kg}$ significantly increased the absolute numbers of Treg on day $5 \mathrm{PI}$ as compared to both control mice and $3 \mathrm{mg} / \mathrm{kg}$ allicin-treated mice (Figure 6A). However, the serum levels of IL-10 were not significantly different between the control and allicin-treated group on either day 3 or day 5 PI (Figure 6B). Similarly, the production of IL-10 by cultured splenocytes was not significantly different between the control and allicin-treated groups (Figure 6C).

\section{Discussion}

Allicin, a sulphur compound produced in garlic, has antibacterial, antifungal and antiparasitic activities. The main mechanism and mode of action of allicin is generally considered to be its reaction with the $\mathrm{SH}$ group on cysteine residues of enzymes in the pathogens, resulting in their inactivation [52,53]. The antiparasitic activity of allicin on Plasmodium and Trypanosoma was attributed to the inhibition of cysteine proteases in these parasites [32]. Previous studies have shown that allicin inhibited $P$. berghei circumsporozoite protein processing and prevented sporozoite invasion of host cells in vitro as well as protected the $P$. berghei-infected mice from early death [30,54]. This study assessed the immunomodulatory effect of allicin on P. yoelii 17XL-infected mice. The results showed the anti-malarial activity of allicin in P. yoelii $17 \mathrm{XL}$ infected mice was partially due to its enhancement of the pro-inflammatory immune response by expanding the populations of $\mathrm{CD}^{+} \mathrm{T}$ cells, mDCs and macrophages as well as stimulating DCs maturation.

Pro-inflammatory mediators play an important role in controlling parasitaemia at the early stage during $P$. yoelii 17XL infection $[6,11,55,56]$. Expansion of macrophages and elevated TNF level are critical for controlling parasitaemia [57], while IFN- $\gamma$ forms a central mediator of protective immune responses against pre-erythrocytic and blood-stage malaria parasites [58]. During the acute phase of malaria infection, native $\mathrm{T}$ cells may be stimulated to produce IFN- $\gamma$ and TNF [59]. Allicin treatment 


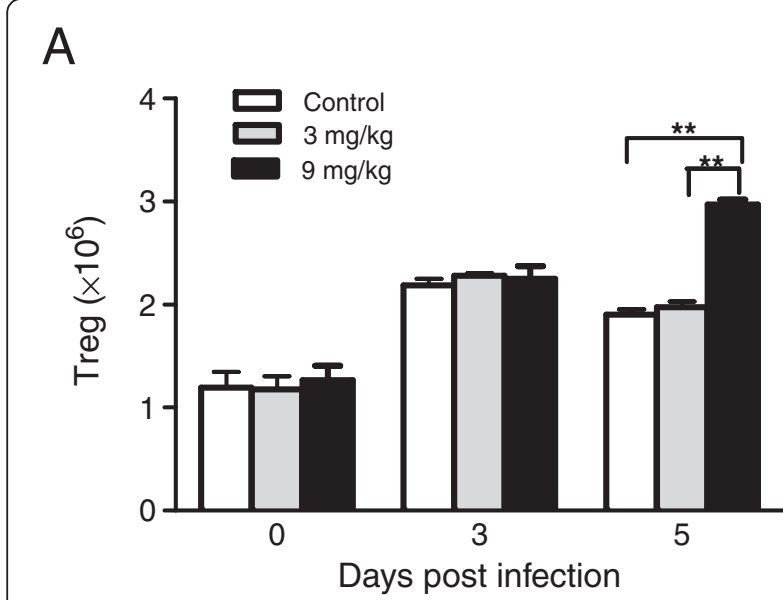

B

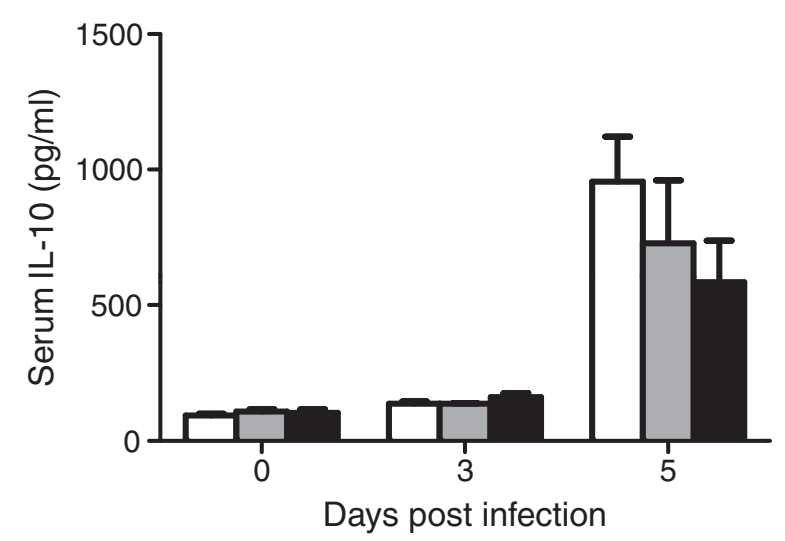

C

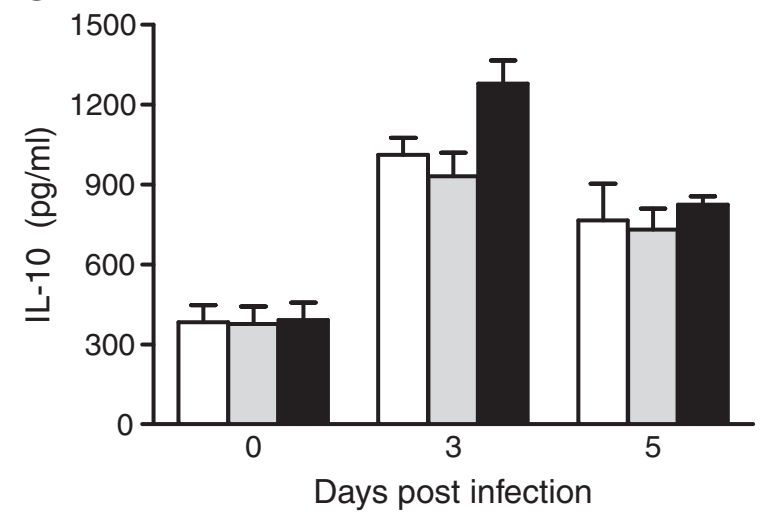

Figure 6 Effects of allicin treatments on Treg and IL-10 level during $P$. yoelii 17XL infection. (A) Absolute numbers of Treg at various time points as detected by flow cytometry analysis. (B) The concentrations of IL-10 in sera on day 3 and 5 PI. (C) The concentrations of IL-10 produced by cultured splenocytes. Concentrations of IL-10 were determined by ELISA. Data expressed as the mean with SEM ( $n=3$ mice per group). Results are representative of three independent experiments. Asterisks indicate statistically significant differences $(* *: P<0.01)$ between groups. significantly elevated the levels of these pro-inflammatory mediators (IFN- $\gamma$, TNF and NO) in a dose-dependent manner in P. yoelii 17XL-infected BALB/c mice, consistent with allicin's function as an immune stimulant [34-37]. To a lower extent, allicin treatment also enhanced the production of IL-12p70 of cultured spleen cells, another indicator for enhanced Th1 response. Finally, allicin treatment stimulated expansion of $\mathrm{CD} 4^{+} \mathrm{T}$ cells, which further supports the activation of Th1 immune response. As a hallmark of Th2 immune response, IL-4 level in allicin treated mice was comparable to that in control mice, indicating that allicin treatment did not affect Th2 immune response during early $P$. yoelii $17 \mathrm{XL}$ infection.

DCs bridge the innate and adaptive immune response as APCs via antigen presentation to helper T cells, which can activate native $\mathrm{T}$ cells and polarize $\mathrm{CD} 4^{+} \mathrm{T}$ cells response [60]. Stimulation of T-cell responses, and more importantly, induction of Th1 cell development, is associated with maturation of DCs as well as their production of Th1 cytokines [61,62]. Thus, the strategy to improve the maturation and activation of DCs is key to the initiation of a protective immune response against malaria infection. The results suggested that allicin treatment could significantly promote the maturation of DCs with increasing expression of the co-stimulatory molecules.

Toll like receptors (TLRs) expressed on the innate immune cells (such as DCs) engaged in the recognition of constituents of protozoan parasites [63,64]. Upon TLR-driven activation, DCs produce pro-inflammatory and protective cytokines that contribute to innate immunity. TLR9 mediates innate immune activation by the malaria haemozoin [65] and protein-DNA complex [66]. TLR9 mediates parasite recognition and initiates IFN- $\gamma$ production to prime host innate responses against malaria $[67,68]$. In summary, allicin could expand the population of TLR9expressing DCs, resulting in increases of the IFN- $\gamma$ level.

Another aspect of allicin's immunomodulatory effect is down-regulation of pro-inflammatory response. Allicin could reduce the TNF level in a dose-dependent manner and suppress both spontaneous and TNF stimulated secretion of cytokines IL-1, IL- 6 and IL-8 $[38,69]$. This is largely due to regulation of the host Treg and antiinflammatory cytokine IL-10. Depletion of Treg protects BALB/c mice infected with $P$. yoelii 17XL from overwhelming parasitaemia and death [70]. Therefore, Treg provide an essential mechanism for the parasites to evade host-mediated immunity. In addition, TLR9 engagement in DCs is required for natural Treg activation by malaria parasites [71]. The higher dose of allicin treatment increased the TLR9 expression on DCs on day 5 PI, which in turn increased the number of Treg. However, the level of IL-10 was not correspondently elevated, suggesting that 
allicin treatment did not drastically modify the function of Treg during the acute malaria infection.

In summary, allicin treatment can protect host against malaria infection by activating pro-inflammatory immune responses in a dose-dependent manner. The immunestimulatory effect of allicin is characterized by induced mature DCs during early phase of $P$. yoelii 17XL infection, which leads to increased levels of pro-inflammatory mediators from proliferative macrophages and $\mathrm{CD} 4^{+} \mathrm{T}$ cells. The results provide important insights into the in vivo parasite-inhibitory mechanism of allicin, which suggests the involvement of both direct inhibition of parasite enzymes and stimulation of antiparasitic immune response of the host.

\section{Conclusions}

Allicin treatment could enhance host immunity against malaria infection in a rodent malaria model. It was observed that treatment with allicin during $P$. yoelii 17XL infection could enhance host innate and adaptive immunity evidenced by elevated numbers of macrophages and $\mathrm{CD}^{+}{ }^{+} \mathrm{T}$ cells and cytokines. In addition, allicin treatment promoted the expansion and maturation of DCs, which play an essential role in initiating adaptive immunity. However, the function of Treg was not altered by allicin treatment. Collective findings from this study suggest that allicin partially protects host against malaria infection through enhancement of the host's innate and adaptive immune responses.

\section{Competing interests}

The authors declare that they have no competing interests.

\section{Authors' contributions}

YF carried out the flow cytometry, statistical analysis and drafted the manuscript. $X Z$ performed detection of cytokines and $\mathrm{NO}_{2}^{-}$concentration. YJ and HS helped to revise the manuscript. YC and LC conceived the study and participated in the design of the study. All authors read and approved the final manuscript.

\section{Acknowledgements}

This work was supported by grants from the National Natural Science Foundation of China (30800962).

\section{Author details \\ ${ }^{1}$ Department of Immunology, College of Basic Medical Sciences, China Medical University, Shenyang, Liaoning, China. ${ }^{2}$ Department of Laboratory Medicine, the First Hospital of China Medical University, Shenyang, Liaoning, China. ${ }^{3}$ The Key Laboratory of AIDS Immunology of Ministry of Health, the First Hospital of China Medical University, Shenyang, Liaoning, China. ${ }^{4}$ Department of Entomology, Pennsylvania State University, University Park, PA, USA}

Received: 6 May 2012 Accepted: 22 July 2012

Published: 8 August 2012

\section{References}

1. WHO: World Malaria Report 2009. Geneva: World Health Organization; 2010.

2. Wykes MN, Good MF: What have we learnt from mouse models for the study of malaria? Eur J Immunol 2009, 39:2004-2007.
3. Stevenson MM, Riley EM: Innate immunity to malaria. Nat Rev Immunol 2004, 4:169-180.

4. Schofield L, Grau GE: Immunological processes in malaria pathogenesis. Nat Rev Immunol 2005, 5:722-735.

5. Urban BC, Ing R, Stevenson MM: Early interactions between blood-stage Plasmodium parasites and the immune system. Curr Top Microbiol Immunol 2005, 297:25-70.

6. Amante FH, Good MF: Prolonged Th1-like response generated by a Plasmodium yoelii-specific T cell clone allows complete clearance of infection in reconstituted mice. Parasite Immunol 1997, 19:111-126.

7. Wang R, Charoenvit Y, Corradin G, De La Vega P, Franke ED, Hoffman SL: Protection against malaria by Plasmodium yoelii sporozoite surface protein 2 linear peptide induction of CD4+ T cell- and IFN-gammadependent elimination of infected hepatocytes. J Immunol 1996, 157:4061-4067.

8. Awasthi A, Kumar A, Upadhyay SN, Yamada T, Matsunaga Y: Nitric oxide protects against chloroquine resistant Plasmodium yoelii nigeriensis parasites in vitro. Exp Parasitol 2003, 105:184-191.

9. Couper KN, Blount DG, Hafalla JC, van Rooijen N, de Souza JB, Riley EM: Macrophage-mediated but gamma interferon-independent innate immune responses control the primary wave of Plasmodium yoelii parasitemia. Infect Immun 2007, 75:5806-5818.

10. Cambos M, Belanger B, Jacques A, Roulet A, Scorza T: Natural regulatory (CD4 + CD25 + FOXP3+) T cells control the production of pro-inflammatory cytokines during Plasmodium chabaudi adami infection and do not contribute to immune evasion. Int J Parasito/ 2008, 38:229-238.

11. Wu Y, Wang QH, Zheng L, Feng H, Liu J, Ma SH, Cao YM: Plasmodium yoelii: distinct $\mathrm{CD} 4(+) \mathrm{CD} 25(+)$ regulatory $T$ cell responses during the early stages of infection in susceptible and resistant mice. Exp Parasitol 2007, 115:301-304.

12. Bueno LL, Morais CG, Araujo FF, Gomes JA, Correa-Oliveira R, Soares IS, Lacerda MV, Fujiwara RT, Braga EM: Plasmodium vivax: induction of $\mathrm{CD} 4+\mathrm{CD} 25+$ FoxP3 + regulatory T cells during infection are directly associated with level of circulating parasites. PLoS One 2010, 5:e9623.

13. Steinman RM, Hemmi H: Dendritic cells: translating innate to adaptive immunity. Curr Top Microbiol Immunol 2006, 311:17-58.

14. Manicassamy S, Pulendran B: Modulation of adaptive immunity with Tolllike receptors. Semin Immunol 2009, 21:185-193.

15. Butt MS, Sultan MT, Butt MS, labal J: Garlic: nature's protection against physiological threats. Crit Rev Food Sci Nutr 2009, 49:538-551.

16. Goncagul G, Ayaz E: Antimicrobial effect of garlic (Allium sativum). Recent Pat Antiinfect Drug Discov 2010, 5:91-93.

17. Ankri S, Mirelman D: Antimicrobial properties of allicin from garlic. Microbes Infect 1999, 1:125-129.

18. Ramoutar RR, Brumaghim JL: Antioxidant and anticancer properties and mechanisms of inorganic selenium, oxo-sulfur, and oxo-selenium compounds. Cell Biochem Biophys 2010, 58:1-23.

19. Sun $\mathrm{X}, \mathrm{Ku}$ DD: Allicin in garlic protects against coronary endothelial dysfunction and right heart hypertrophy in pulmonary hypertensive rats. Am J Physiol Heart Circ Physiol 2006, 291:H2431-H2438.

20. Antony ML, Singh SV: Molecular mechanisms and targets of cancer chemoprevention by garlic-derived bioactive compound diallyl trisulfide. Indian J Exp Biol 2011, 49:805-816.

21. Nagini S: Cancer chemoprevention by garlic and its organosulfur compounds-panacea or promise? Anticancer Agents Med Chem 2008, 8:313-321.

22. Anthony JP, Fyfe L, Smith H: Plant active components - a resource for antiparasitic agents? Trends Parasitol 2005, 21:462-468.

23. Wabwoba BW, Anjili CO, Ngeiywa MM, Ngure PK, Kigondu EM, Ingonga J, Makwali J: Experimental chemotherapy with Allium sativum (Liliaceae) methanolic extract in rodents infected with Leishmania major and Leishmania donovani. J Vector Borne Dis 2010, 47:160-167.

24. Gamboa-Leon MR, Aranda-Gonzalez I, Mut-Martin M, Garcia-Miss MR, Dumonteil E: In vivo and in vitro control of Leishmania mexicana due to garlic-induced NO production. Scand J Immunol 2007, 66:508-514.

25. Mantawy MM, Ali HF, Rizk MZ: Therapeutic effects of Allium sativum and Allium cepa in Schistosoma mansoni experimental infection. Rev Inst Med Trop São Paulo 2011, 53:155-163.

26. Nahed HA, Hoda AT, Yomna IM: Effects of garlic on albino mice experimentally infected with Schistosoma mansoni: a parasitological and ultrastructural study. Trop Biomed 2009, 26:40-50. 
27. Lun ZR, Burri C, Menzinger M, Kaminsky R: Antiparasitic activity of diallyl trisulfide (Dasuansu) on human and animal pathogenic protozoa (Trypanosoma sp., Entamoeba histolytica and Giardia lamblia) in vitro. Ann Soc Belg Med Trop 1994, 74:51-59.

28. Ankri S, Miron T, Rabinkov A, Wilchek M, Mirelman D: Allicin from garlic strongly inhibits cysteine proteinases and cytopathic effects of Entamoeba histolytica. Antimicrob Agents Chemother 1997, 41:2286-2288.

29. Perez HA, De la Rosa M, Apitz R: In vivo activity of ajoene against rodent malaria. Antimicrob Agents Chemother 1994, 38:337-339.

30. Coppi A, Cabinian M, Mirelman D, Sinnis P: Antimalarial activity of allicin, a biologically active compound from garlic cloves. Antimicrob Agents Chemother 2006, 50:1731-1737.

31. Amagase $\mathrm{H}$ : Clarifying the real bioactive constituents of garlic. J Nutr 2006, 136:716S-725S.

32. Waag T, Gelhaus C, Rath J, Stich A, Leippe M, Schirmeister T: Allicin and derivates are cysteine protease inhibitors with antiparasitic activity. Bioorg Med Chem Lett 2010, 20:5541-5543.

33. Amagase $H$, Petesch $B L$, Matsuura $H$, Kasuga S, Itakura $Y$ : Intake of garlic and its bioactive components. J Nutr 2001, 131:955S-962S.

34. Kyo E, Uda N, Kasuga S, Itakura Y: Immunomodulatory effects of aged garlic extract. J Nutr 2001, 131:1075S-1079S.

35. Lau BH, Yamasaki T, Gridley DS: Garlic compounds modulate macrophage and T-lymphocyte functions. Mol Biother 1991, 3:103-107.

36. Bhattacharyya M, Girish GV, Karmohapatra SK, Samad SA, Sinha AK: Systemic production of IFN-alpha by garlic (Allium sativum) in humans. J Interferon Cytokine Res 2007, 27:377-382.

37. Morihara N, Sumioka I, Moriguchi T, Uda N, Kyo E: Aged garlic extract enhances production of nitric oxide. Life Sci 2002, 71:509-517.

38. Hodge $G$, Hodge $S$, Han P: Allium sativum (garlic) suppresses leukocyte inflammatory cytokine production in vitro: potential therapeutic use in the treatment of inflammatory bowel disease. Cytometry 2002, 48:209-215.

39. Ghazanfari T, Hassan ZM, Ebtekar M, Ahmadiani A, Naderi G, Azar A: Garlic induces a shift in cytokine pattern in Leishmania major-infected BALB/C mice. Scand J Immunol 2000, 52:491-495.

40. Ghazanfari T, Hassan ZM, Khamesipour A: Enhancement of peritoneal macrophage phagocytic activity against Leishmania major by garlic (Allium sativum) treatment. J Ethnopharmacol 2006, 103:333-337.

41. Zhu X, Pan Y, Zheng L, Cui L, Cao Y: Polysaccharides from the Chinese medicinal herb Achyranthes bidentata enhance anti-malarial immunity during Plasmodium yoelii 17XL infection in mice. Malar J 2012, 11:49.

42. Cao YM, Tsuboi T, Torii M: Nitric oxide inhibits the development of Plasmodium yoelii gametocytes into gametes. Parasitol Int 1998, 47:157-166.

43. Zhou LD, Zhang QH, Zhang Y, Liu J, Cao YM: The shiitake mushroomderived immuno-stimulant lentinan protects against murine malaria blood-stage infection by evoking adaptive immune-responses. Int Immunopharmacol 2009, 9:455-462.

44. Sedegah M, Finkelman F, Hoffman SL: Interleukin 12 induction of interferon gamma-dependent protection against malaria. Proc Natl Acad Sci U S A 1994, 91:10700-10702.

45. Doolan DL, Hoffman SL: IL-12 and NK cells are required for antigenspecific adaptive immunity against malaria initiated by CD8+ T cells in the Plasmodium yoelii model. J Immunol 1999, 163:884-892.

46. Su Z, Stevenson MM: IL-12 is required for antibody-mediated protective immunity against blood-stage Plasmodium chabaudi AS malaria infection in mice. J Immunol 2002, 168:1348-1355.

47. Stephens R, Albano FR, Quin S, Pascal BJ, Harrison V, Stockinger B, Kioussis D, Weltzien HU, Langhorne J: Malaria-specific transgenic CD4(+) T cells protect immunodeficient mice from lethal infection and demonstrate requirement for a protective threshold of antibody production for parasite clearance. Blood 2005, 106:1676-1684.

48. Ing R, Segura M, Thawani N, Tam M, Stevenson MM: Interaction of mouse dendritic cells and malaria-infected erythrocytes: uptake, maturation, and antigen presentation. J Immunol 2006, 176:441-450

49. Schwartz IF, Hershkovitz R, laina A, Gnessin E, Wollman Y, Chernichowski T, Blum M, Levo Y, Schwartz D: Garlic attenuates nitric oxide production in rat cardiac myocytes through inhibition of inducible nitric oxide synthase and the arginine transporter CAT-2 (cationic amino acid transporter-2). Clin Sci (Lond) 2002, 102:487-493.

50. Hasan N, Yusuf N, Toossi Z, Islam N: Suppression of Mycobacterium tuberculosis induced reactive oxygen species (ROS) and TNF-alpha mRNA expression in human monocytes by allicin. FEBS Lett 2006, 580:2517-2522.
51. Bruck R, Aeed H, Brazovsky E, Noor T, Hershkoviz R: Allicin, the active component of garlic, prevents immune-mediated, concanavalin Ainduced hepatic injury in mice. Liver Int 2005, 25:613-621.

52. Kyung $\mathrm{KH}$ : Antimicrobial properties of allium species. Curr Opin Biotechnol 2012, 23:142-147.

53. Fujisawa $H$, Watanabe $K$, Suma K, Origuchi K, Matsufuji $H$, Seki T, Ariga T: Antibacterial potential of garlic-derived allicin and its cancellation by sulfhydryl compounds. Biosci Biotechnol Biochem 2009, 73:1948-1955.

54. Rennenberg A, Lehmann C, Heitmann A, Witt T, Hansen G, Nagarajan K, Deschermeier C, Turk V, Hilgenfeld R, Heussler VT: Exoerythrocytic Plasmodium parasites secrete a cysteine protease inhibitor involved in sporozoite invasion and capable of blocking cell death of host hepatocytes. PLOS Pathog 2010, 6:e1000825.

55. Chen G, Feng H, Liu J, Qi ZM, Wu Y, Guo SY, Li DM, Wang JC, Cao YM: Characterization of immune responses to single or mixed infections with P. yoelii 17XL and P. chabaudi AS in different strains of mice. Parasitol Int 2010, 59:400-406.

56. Taylor-Robinson AW, Phillips RS, Severn A, Moncada S, Liew FY: The role of TH1 and TH2 cells in a rodent malaria infection. Science 1993, 260:1931-1934.

57. Taverne J, Sheikh N, de Souza JB, Playfair JH, Probert L, Kollias G: Anaemia and resistance to malaria in transgenic mice expressing human tumour necrosis factor. Immunology 1994, 82:397-403.

58. McCall MB, Sauerwein RW: Interferon-gamma-central mediator of protective immune responses against the pre-erythrocytic and blood stage of malaria. J Leukoc Biol 2010, 88:1131-1143.

59. Perry JA, Rush A, Wilson RJ, Olver CS, Avery AC: Dendritic cells from malariainfected mice are fully functional APC. J Immunol 2004, 172:475-482.

60. Banchereau J, Steinman RM: Dendritic cells and the control of immunity. Nature 1998, 392:245-252.

61. Wykes MN, Liu XQ, Beattie L, Stanisic DI, Stacey KJ, Smyth MJ, Thomas R, Good MF: Plasmodium strain determines dendritic cell function essential for survival from malaria. PLoS Pathog 2007, 3:e96

62. Ing R, Stevenson MM: Dendritic cell and NK cell reciprocal cross talk promotes gamma interferon-dependent immunity to blood-stage Plasmodium chabaudi AS infection in mice. Infect Immun 2009, 77:770-782

63. Iwasaki A, Medzhitov R: Toll-like receptor control of the adaptive immune responses. Nat Immunol 2004, 5:987-995.

64. Pasare C, Medzhitov R: Toll-like receptors: linking innate and adaptive immunity. Adv Exp Med Biol 2005, 560:11-18.

65. Coban C, Ishii KJ, Kawai T, Hemmi H, Sato S, Uematsu S, Yamamoto M, Takeuchi O, Itagaki S, Kumar N, Horii T, Akira S: Toll-like receptor 9 mediates innate immune activation by the malaria pigment hemozoin. $J$ Exp Med 2005, 201:19-25.

66. Wu X, Gowda NM, Kumar S, Gowda DC: Protein-DNA complex is the exclusive malaria parasite component that activates dendritic cells and triggers innate immune responses. J Immunol 2010, 184:4338-4348.

67. Kalis C, Gumenscheimer M, Freudenberg N, Tchaptchet S, Fejer G, Heit A Akira S, Galanos C, Freudenberg MA: Requirement for TLR9 in the immunomodulatory activity of Propionibacterium acnes. J Immunol 2005 174:4295-4300

68. Franklin BS, Parroche P, Ataide MA, Lauw F, Ropert C, de Oliveira RB, Pereira D, Tada MS, Nogueira P, da Silva LH, Bjorkbacka H, Golenbock DT, Gazzinelli RT: Malaria primes the innate immune response due to interferongamma induced enhancement of toll-like receptor expression and function. Proc Natl Acad Sci U S A 2009, 106:5789-5794.

69. Lang A, Lahav M, Sakhnini E, Barshack I, Fidder HH, Avidan B, Bardan E, Hershkoviz R, Bar-Meir S, Chowers Y: Allicin inhibits spontaneous and TNFalpha induced secretion of proinflammatory cytokines and chemokines from intestinal epithelial cells. Clin Nutr 2004, 23:1199-1208.

70. Hisaeda H, Maekawa Y, Iwakawa D, Okada H, Himeno K, Kishihara K, Tsukumo S, Yasutomo K: Escape of malaria parasites from host immunity requires CD4+ CD25+ regulatory T cells. Nat Med 2004, 10:29-30.

71. Hisaeda H, Tetsutani K, Imai T, Moriya C, Tu L, Hamano S, Duan X, Chou B, Ishida H, Aramaki A, Shen J, Ishii KJ, Coban C, Akira S, Takeda K, Yasutomo K, Torii M, Himeno K: Malaria parasites require TLR9 signaling for immune evasion by activating regulatory T cells. J Immunol 2008, 180:2496-2503.

doi:10.1186/1475-2875-11-268

Cite this article as: Feng et al:: Allicin enhances host pro-inflammatory immune responses and protects against acute murine malaria infection. Malaria Journal 2012 11:268. 